\begin{tabular}{lcccr} 
T H E & A R C H I V E & O F & M E C H A N I C A L & E N G I N E E R I N G \\
\hline VOL. LVIII & 2011 & Number 4
\end{tabular}

10.2478/v10180-011-0024-4

Key words: thin-walled structures, blast wave load, fluid-structure interaction, ALE, Finite Element, LS-Dyna

\title{
VULNERABILITY ANALYSIS OF AIRCRAFT FUSELAGE SUBJECTED TO INTERNAL EXPLOSION
}

\begin{abstract}
The most important task in tests of resistance of aircraft structures to the terrorist threats is to determine the vulnerability of thin-walled structures to the blast wave load. For obvious reasons, full-scale experimental investigations are carried out exceptionally. In such cases, numerical simulations are very important. They make it possible to tune model parameters, yielding proper correlation with experimental data. Basing on preliminary numerical analyses - experiment can be planned properly. The paper presents some results of dynamic simulations of finite element (FE) models of a medium-size aircraft fuselage. Modeling of C4 detonation is also discussed. Characteristics of the materials used in FE calculations were obtained experimentally. The paper describes also the investigation of sensitivity of results of an explicit dynamic study to FE model parameters in a typical fluid-structure interaction (FSI) problem (detonation of a C4 explosive charge). Three cases of extent of the Eulerian mesh (the domain which contains air and a charge) were examined. Studies have shown very strong sensitivity of the results to chosen numerical models of materials, formulations of elements, assumed parameters etc. Studies confirm very strong necessity of the correlation of analysis results with experimental data. Without such a correlation, it is difficult to talk about the validation of results obtained from the "explicit" codes.
\end{abstract}

\section{Introduction}

Due to the growing threat of terrorist attacks some experimental work (e.g. [1]) and numerical analyses have been performed to study the dynamic behavior of a fuselage subjected to blast pressure loads. Unfortunately the most of experimental data are not accessible to the open research community, therefore numerical modeling of aircraft explosions plays so important role.

* Faculty of Power and Aeronautical Engineering, Warsaw University of Technology, Nowowiejska 24 Street,00-665 Warsaw, Poland; E-mail: adam.dacko@meil.pw.edu.pl

** Faculty of Power and Aeronautical Engineering, Warsaw University of Technology, Nowowiejska 24 Street,00-665 Warsaw, Poland; E-mail: jtoczyski@meil.pw.edu.pl 
Some of these finite element simulations have attempted to predict (simultaneously) the blast wave propagation and related structural damage [2], [3]. Other numerical investigations concentrate mainly on structural damage, e.g. [7].

For obvious reasons, full-scale experimental investigations are carried out exceptionally. In such cases numerical analyses are very useful. They allow one to tune numerical model parameters for proper correlation of results with experimental measurements.

In the paper, the numerical analysis of the explosion of a $\mathrm{C} 4$ charge of mass $m_{0}$ in a medium-size passenger airplane is discussed. These studies are continuation of the authors' research presented in the Journal of KONES [4]. In order to investigate the dynamic behavior of a fuselage, numerical simulations using the commercial explicit FE code LS-Dyna V971 were performed, for two different locations of the charge relative to the fuselage structure. In the paper, selected elements of investigation of sensitivity of results to details of modeling of a typical fluid-structure interaction problem are also discussed.

\section{FE modeling}

\subsection{Geometry}

The FE model represents a simplified typical section of a medium airplane fuselage (Fig. 1), which was designed by Hellenic Aerospace Industry [5]. The fuselage is meshed with ca. 160,000 shell elements using the Belytschko-Leviathan shell formulation [6]. Mesh density can be observed e.g. in Figs. 12, 14 or 16.

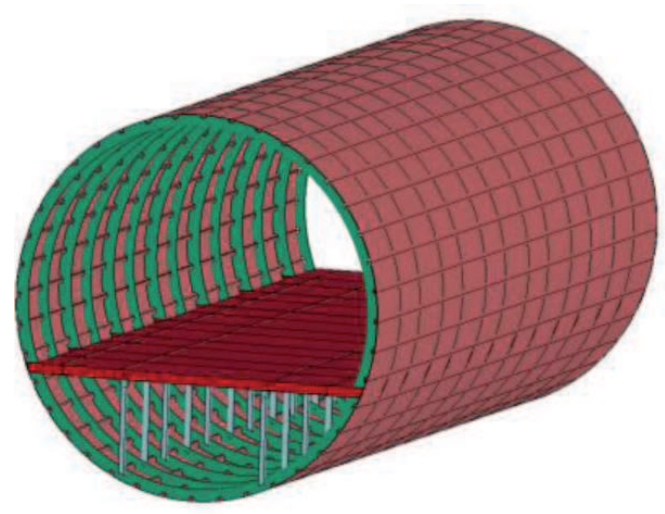

Fig. 1. Geometry of the FE model (it is NOT the mesh) 


\subsection{Material properties}

The airplane structure (excluding floor and bolts) is made of aluminum alloy (AL2024-T3). The required material constants of AL2024-T3 are as follows:

- mass density: $\rho=2923 \mathrm{~kg} / \mathrm{m}^{3}$,

- Young's modulus: $\mathrm{E}=68.7 \mathrm{GPa}$,

- Poisson's ratio: $v=0.35$,

- plastic strain to failure: $20 \%$.

Fig. 2 describes static characteristic of the material in its plastic range [7]. Strain rate effects were neglected. However, this assumption was verified as acceptable in the analyzed case - see sec. 4.1 of this paper.

The fuselage floor is a sandwich structure (Fig. 3). It is composed of four $0.25 \mathrm{~mm}$ thick GFRP layers (two per each side of the floor) and the Nomex honeycomb core with the thickness of $9 \mathrm{~mm}$.

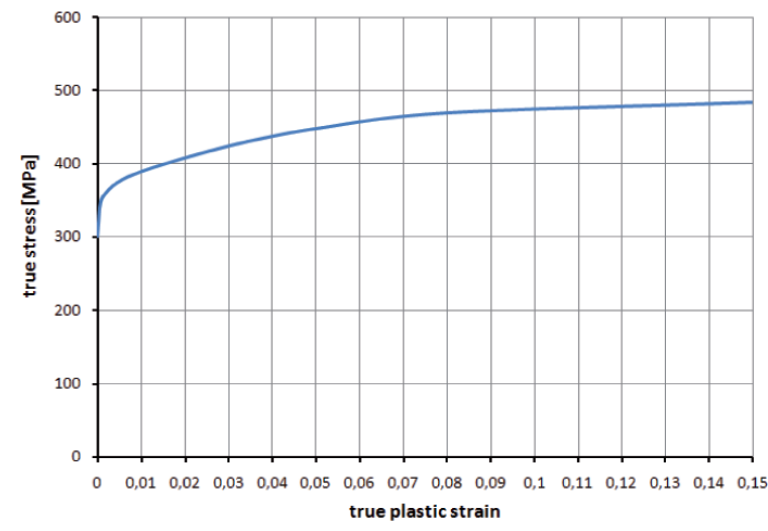

Fig. 2. AL2024-T3 stress-strain characteristic

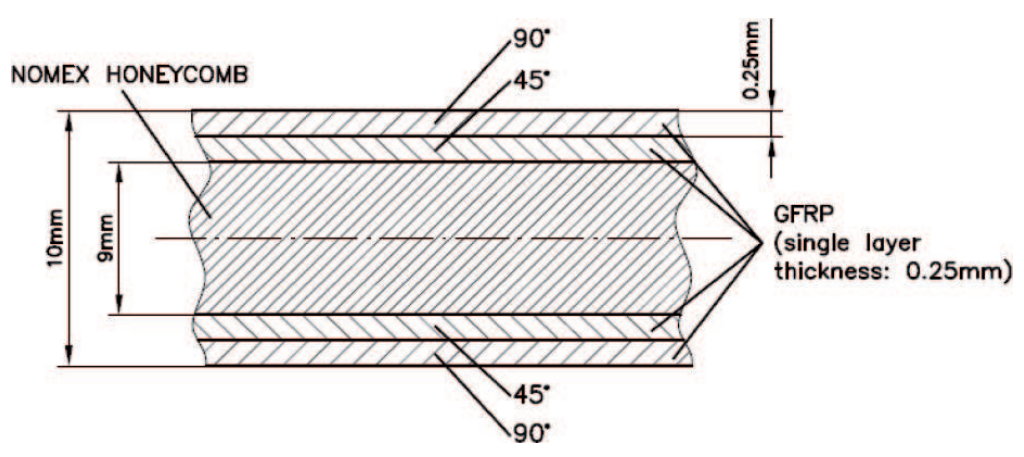

Fig. 3. Fuselage floor cross section 
Riveted connections between parts were modeled using two different techniques. The skin-stiffener connections were modeled using beam elements, the skin-frame connections utilizing spot welds with failure criteria for shear and normal strength.

\subsection{Boundary conditions}

The assumed boundary conditions are shown in Fig. 4. All DOFs of nodes at the right end of the fuselage (skin and floor) are constrained.

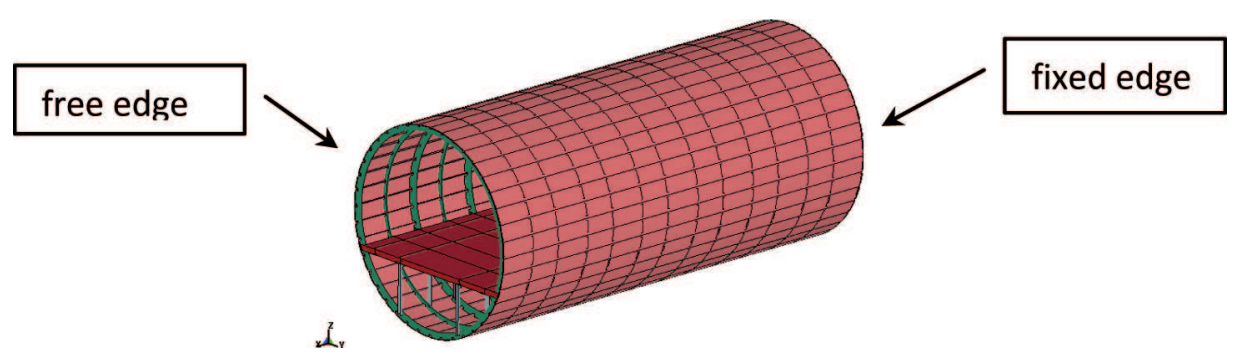

Fig. 4. Boundary conditions

\subsection{Loads}

The structure is loaded by the pressure wave generated by the explosion of a $\mathrm{C} 4$ explosive charge of mass $m_{0}$ (according to Project Consortium Agreement - not disclosed here). Two locations of the charge relative to the fuselage structural members were chosen: "between two frames" (the blast wave will focus on the skin area between two frame beams) and "opposite to a frame" (the blast wave will focus directly on a frame beam).

Simulation of the blast was performed using the Arbitrary LagrangianEulerian (ALE) formulation. Fluid-structure interaction was performed using a dedicated coupling algorithm with an option that allows for erosion of damaged Lagrangian elements.

Available in LS-Dyna option for direct generation of pressure loads, based on the Friedlander equation (procedure named CONWEP) is much simpler in use and much more cost-effective, while preserving good accuracy. Unfortunately, due to complicated model geometry and lots of potential pressure wave reflections - it is not applicable in the analyzed case.

Optionally static pre-stress (e.g. operation loads, gravity) can be applied to the structure as the initial conditions for a dynamic analysis. There are three methods of applying static preloads in LS-Dyna [6]:

- an explicit analysis is used, in which nodal velocities are artificially damped each time step, until the convergence tolerance is reached, 
- the preloaded state is reached by linearly ramping nodal displacements and rotations to prescribed values over 100 time steps (an ASCII file, which describes the initialized state, is required),

- an implicit analysis is used.

After the preloaded state is achieved, the time is set to zero and the normal phase of dynamic solution automatically begins from the preloaded state.

\subsection{The Euler domain}

The Euler domain (C4 charge and air) is meshed with HEXA elements using 1 point ALE multi-material element formulation.

At the free surfaces of the Eulerian mesh the pressure of 1 bar is applied in order to ensure that the analyzed thermodynamic system will, after the explosion, return to the equilibrium state (preserving out-, and in-flow of the air).

The numerical model used also:

- the linear polynomial equation of state (1) as an EOS describing the behavior of air:

$$
\begin{gathered}
p=C_{0}+C_{1} \mu+C_{2} \mu^{2}+C_{3} \mu^{3}+\left(C_{4}+C_{5} \mu+C_{6} \mu^{2}\right) E \\
\mu=\rho / \rho_{0}-1
\end{gathered}
$$

where: $p$ - pressure $[\mathrm{Pa}]$,

$C_{i}$ - polynomial equation coefficients,

$E$ - internal energy per unit reference specific volume $\left[\mathrm{J} / \mathrm{m}^{3}\right]$,

$\rho$ - mass density $\left[\mathrm{kg} / \mathrm{m}^{3}\right]$,

$\rho_{0}-$ initial mass density $\left[\mathrm{kg} / \mathrm{m}^{3}\right]$;

- the JWL equation of state (2) as an EOS describing the burning process of C4:

$$
p=A\left(1-\frac{\omega}{R_{1} V}\right) \exp \left(-R_{1} V\right)+B\left(1-\frac{\omega}{R_{2} V}\right) \exp \left(-R_{2} V\right)+\frac{\omega E}{V}
$$

where: $p$ - pressure [Pa],

$A, B, R_{1}, R_{2}, \omega-$ constants,

$E$ - internal energy per unit reference specific volume $\left[\mathrm{J} / \mathrm{m}^{3}\right]$,

$V$ - relative volume [-].

Typical values of constants in the equations of state and the properties of the explosive charge were accepted from the literature [8].

For the "between frames" case three variants of extent of the Euler domain were discussed (Model 1, Model 2 and Model 3). They are shown in 
Figs. 5, 6 and 7. The cases differ both by length ("axis-wise"), as well as by width ("side-wise") of modeled volume where FSI occurs. It appeared from subsequent analyses, that the 3 . case - which encloses entire cross-section in the Euler domain - gives definitely the best, "physically sensible" results.
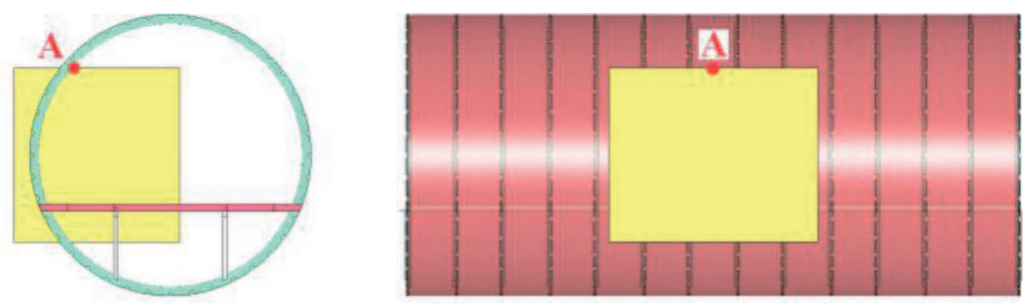

k.

Fig. 5. Model $1-$ dimensions of the Eulerian mesh: $1765 \mathrm{~mm} \times 1855 \mathrm{~mm} \times 2230 \mathrm{~mm}$
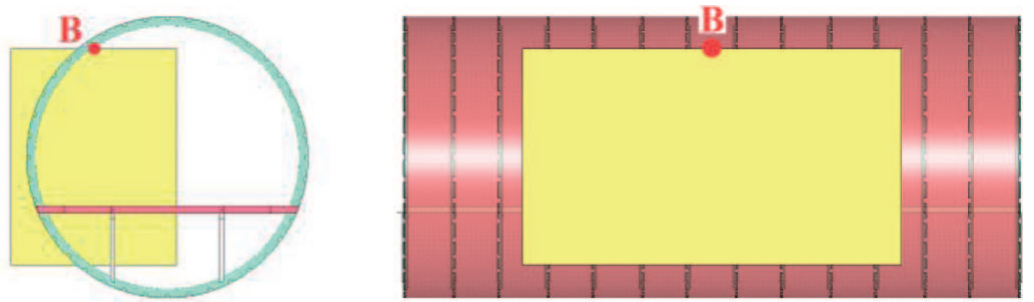

$k \times$

Fig. 6. Model 2 - dimensions of the Eulerian mesh: $1765 \mathrm{~mm} \times 2305 \mathrm{~mm} \times 4030 \mathrm{~mm}$
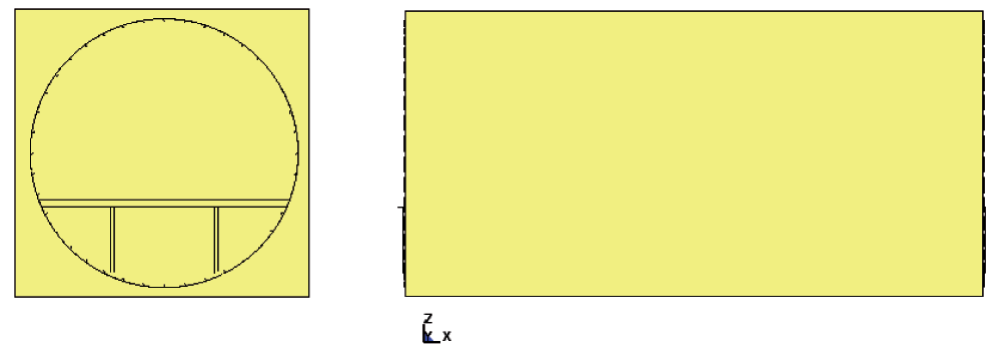

Fig. 7. Model 3 - dimensions of the Eulerian mesh: $3230 \mathrm{~mm} \times 3205 \mathrm{~mm} \times 6525 \mathrm{~mm}$

\section{Discussion of results - deformation}

\subsection{Influence of the size of the Euler domain}

As a result of detonation of the explosive charge, the shock pressure wave is generated. It reaches the skin first and then bounces back, not causing the 
perforation of the skin. In the case of Model 1 and Model 2, about 3ms after the explosion, in the central part of the top surface of the Eulerian mesh (point A in Fig. 5 and point B in Fig. 6), air velocity increases extremely fast (up to a non-physical value). At the same time pressure of the fluid decreases significantly in this area. The disturbance (Fig. 8) leads to large deformation and partial damage of the structure (Fig. 9, Fig. 10). In Model 3, in which the whole cross-section of the analyzed structure is enclosed in the Euler domain, this kind of non-physical behavior of fluid does not occur. The skin is not damaged and the frame beams retain their cylindrical shape (Fig. 11).

Further calculations were performed only for the third version of the mesh - in which the entire fuselage is embedded in the Euler domain.

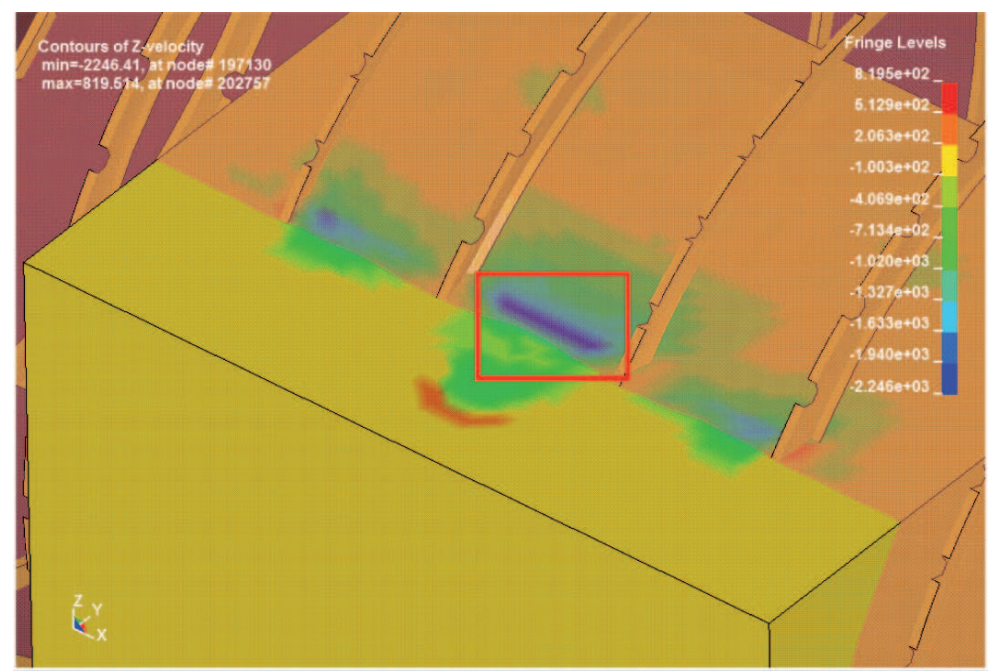

Fig. 8. The Euler domain - non-physical disturbance of the fluid
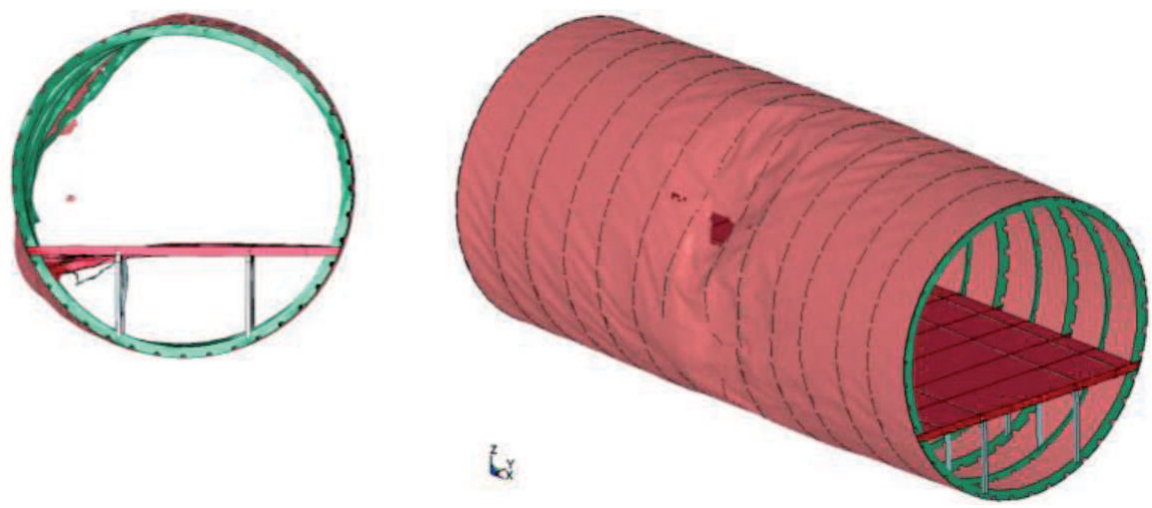

Fig. 9. Model $1-$ deformation of the fuselage at $\mathrm{t}=10 \mathrm{~ms}$ 

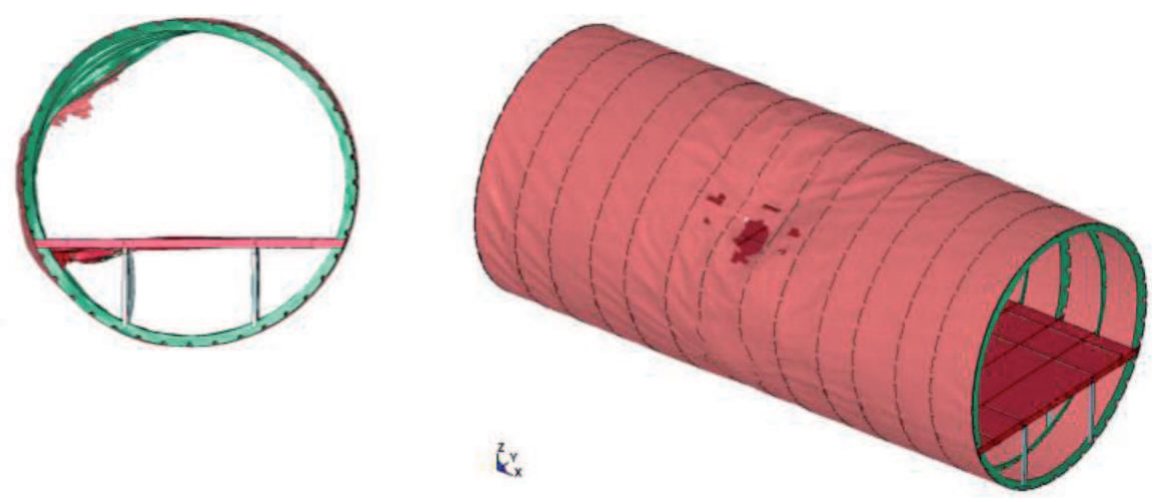

Fig. 10. Model $2-$ deformation of the fuselage at $t=10 \mathrm{~ms}$
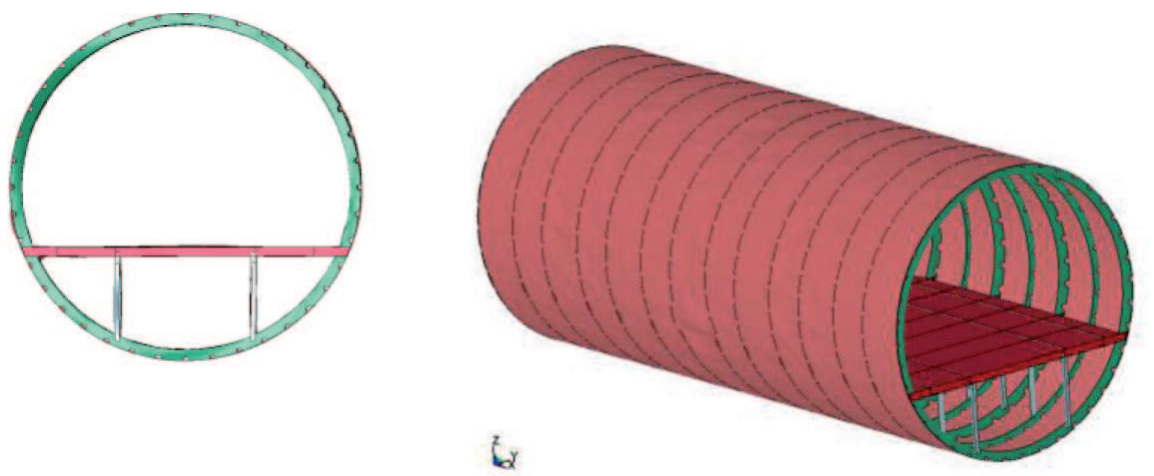

Fig. 11. Model $3-$ deformation of the fuselage at $t=10 \mathrm{~ms}$

\subsection{Deformation of the fuselage}

The deformation of the fuselage subjected to the explosion of a relatively small charge shows no perforation of the skin, however, severe damage of structural members of the reinforcing system occur. In the "between frames" case the blast wave reaches the skin first. The skin deflects, what causes failure of skin-stiffener and skin-frame connectors. Next, unattached parts of the stringers and the frame beams start deforming. Plastic strain in these parts reaches the limit value of $20 \%$. Two frame beams, between which the explosive charge was placed, break in their weakest point - the mousehole area (Fig. 12). Nearby stringers are also destroyed.

In the case "charge opposite to a frame" the blast wave focuses directly on the frame beam. As a result of exceeding the critical (limit) value of plastic strain, the loaded beam is destroyed at the level of the C4 charge (see Fig. 14). 
The maximum value of plastic strain in the skin equals $7.2 \%$ in the "between frames" case and 2.4\% in the "opposite to a frame" case (Figs. 13 and 15 , respectively).

In both considered cases, the floor below the explosive charge was also destroyed.

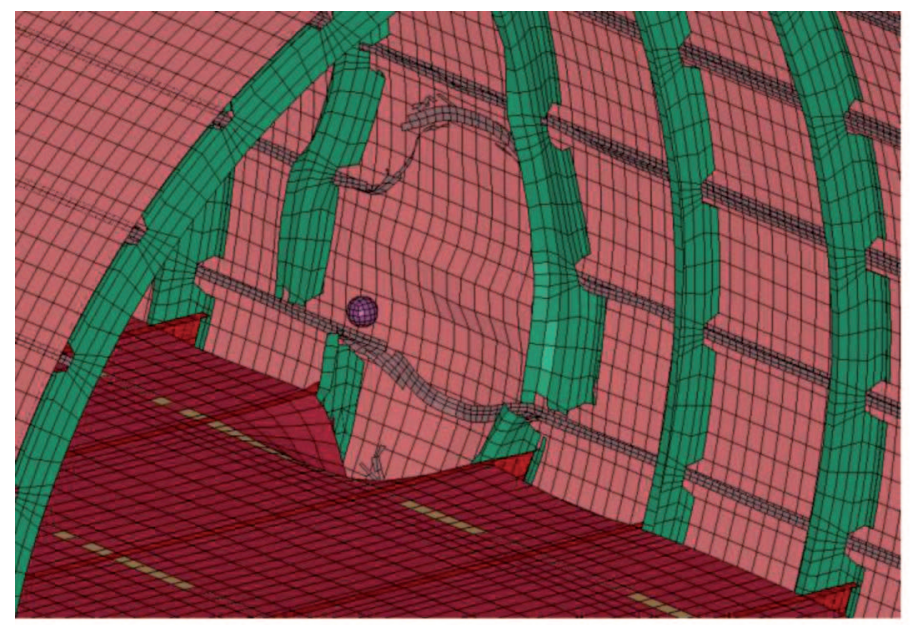

Fig. 12. Fuselage deformation (charge between frames; $t=10 \mathrm{~ms}$ )

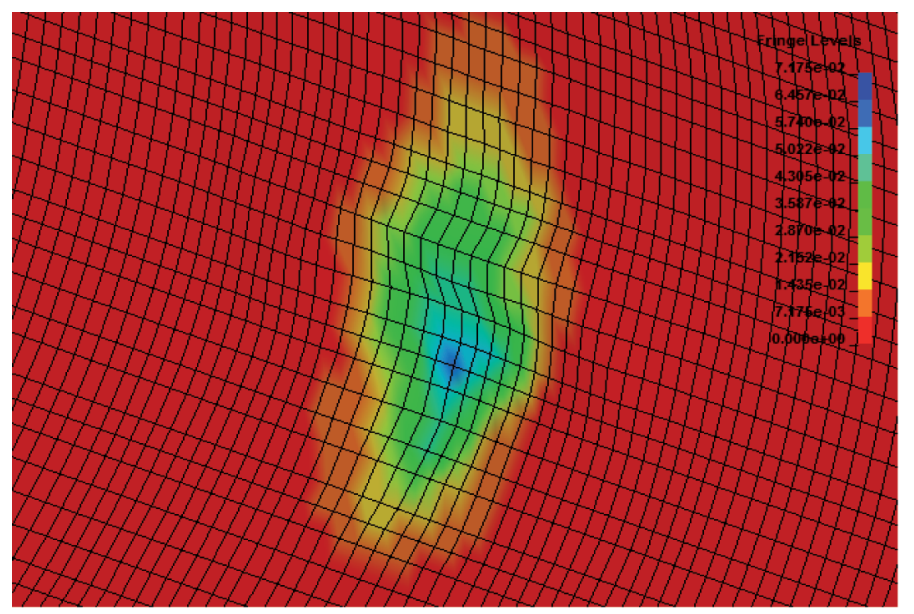

Fig. 13. Skin - plastic strain, max 7.2\% (charge between frames; $\mathrm{t}=10 \mathrm{~ms}$ )

\section{Discussion of results - time/history behavior}

Resultant displacement history plots of a typical, representative node (located on the skin node 81582, marked in Fig. 16), are presented in Fig. 17. 


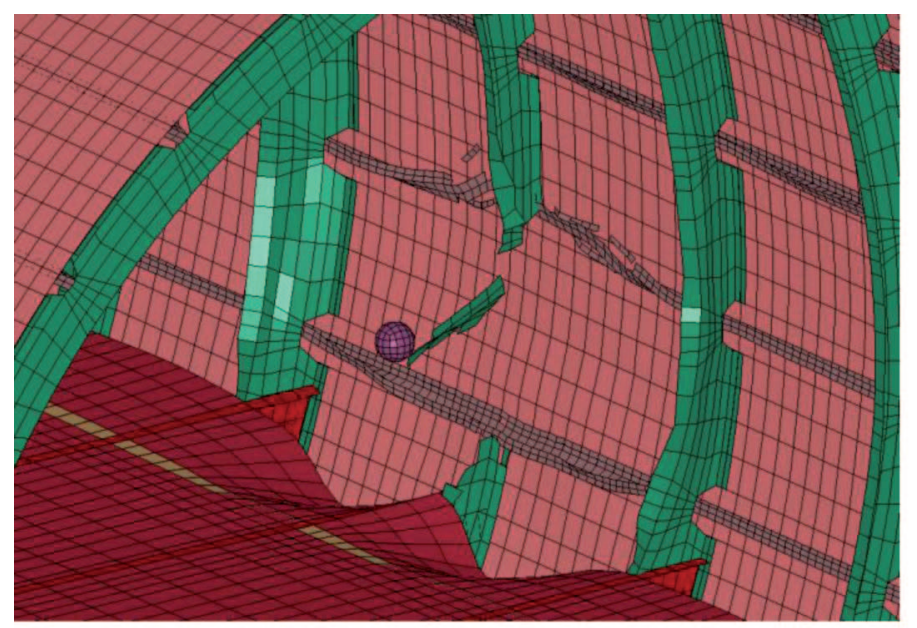

Fig. 14. Fuselage deformation (charge opposite to a frame; $\mathrm{t}=10 \mathrm{~ms}$ )

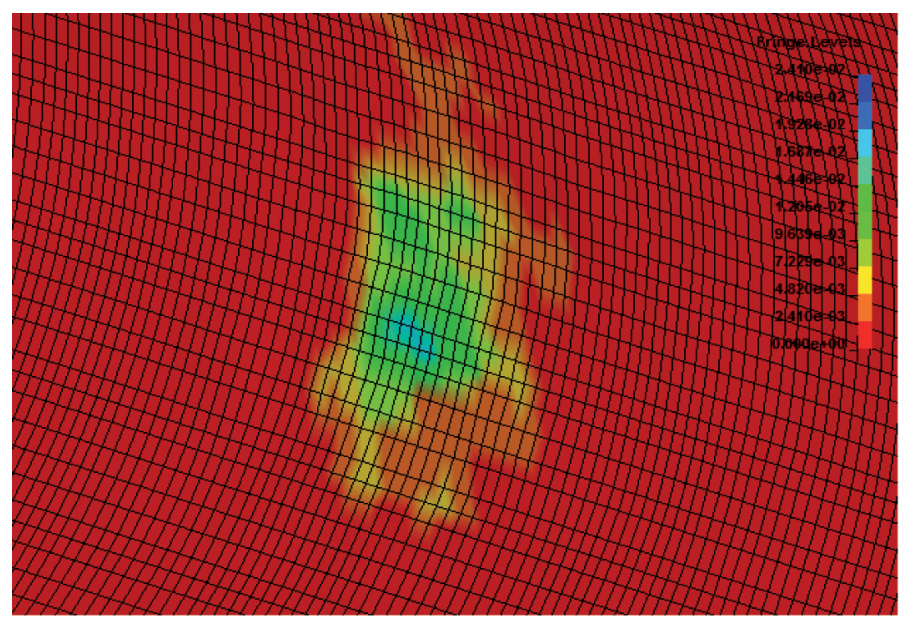

Fig. 15. Skin - plastic strain, $\max 2.4 \%$ (charge opposite to a frame; $\mathrm{t}=10 \mathrm{~ms}$ )

The first considered case, the dark line in Fig. 17, denotes explosive charge location "between frames", i.e. just opposite to this node. In the second case, the light line in Fig. 17, the explosive charge is located opposite to a frame, i.e. slightly offset relative to the considered node.

When the blast wave reaches the skin, the skin is set into oscillation. The first phase of the resultant displacement graphs for both cases is similar. The skin deflects and then bounces back. In the "between frames" case, the value of displacement of the skin that corresponds to the second peak of the curve is almost the same as the value that corresponds to the first peak. In the second case, the curve is smoother and the second maximum is a lot smaller than the first one. 
Lower value of skin displacement in the "opposite to a frame" case results from the fact that the blast wave focuses directly on the relatively rigid frame beam first and later on the more "elastic" skin.

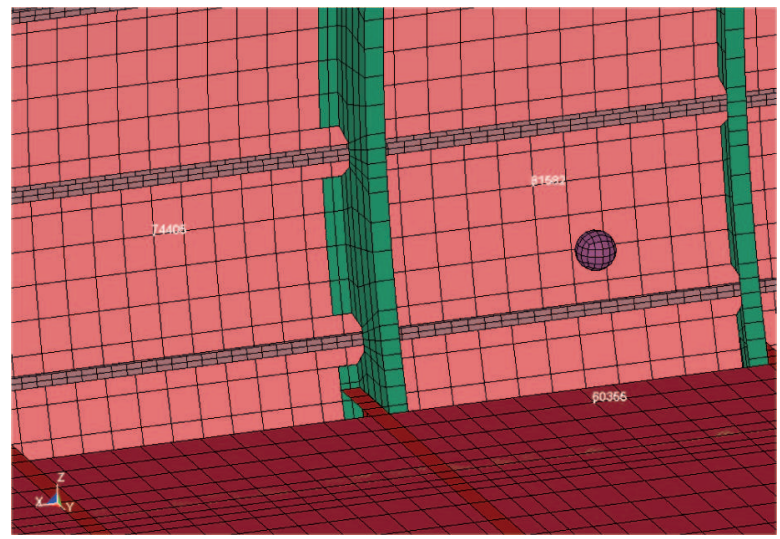

Fig. 16. History node location

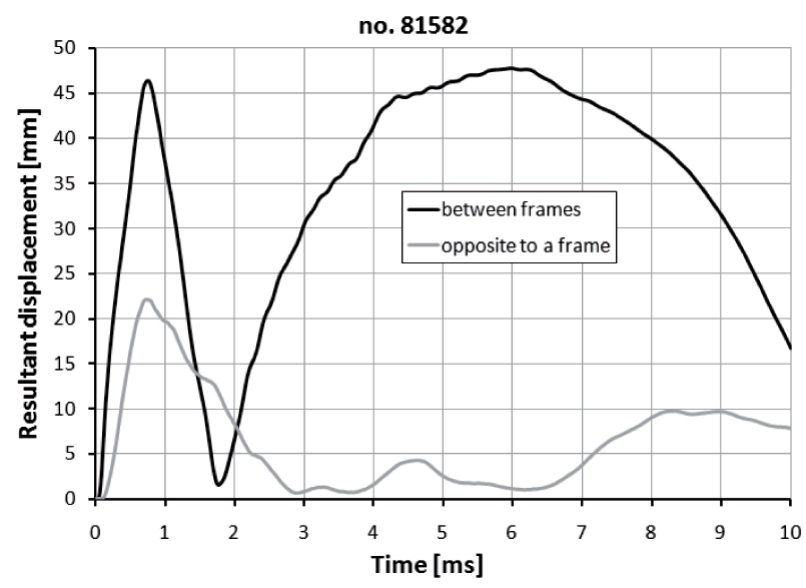

Fig. 17. Resultant displacement (modulus) of the node from Fig. 16

\subsection{Strain rate consideration}

For the case of charge location „between frames”, an additional analysis was performed, checking sensitivity of the results to the strain rate dependent material. The previously applied material model (MAT_024) used tabular definition of the static characteristics of the material curve (piecewise 
approximation). It was replaced by Johnson-Cook material, MAT_015, that takes into account strain-rate $(\dot{\varepsilon})$ in the following form (3):

$$
\sigma_{y}=\left(A+B \bar{\varepsilon}_{p}^{n}\right)\left(1+c \ln \dot{\varepsilon}^{*}\right)\left(1-T_{*}^{m}\right)
$$

where: $\sigma_{y}$ - yield stress [MPa],

$A, B, c, n, m$ - user defined constants,

$\bar{\varepsilon}_{p}$ effective plastic strain [-],

$\dot{\varepsilon}^{*}=\frac{\bar{\varepsilon}_{p}}{\dot{\varepsilon}_{0}} \quad$ effective plastic strain for $\dot{\varepsilon}_{0}=1 s^{-1}$,

$T_{*}=\frac{T-T_{\text {room }}}{T_{\text {melt }}-T_{\text {room }}}-$ non-dimensional relative temperature.

Numerical values of Johnson-Cook constants for AL2024-T3 were adopted after Lesuer [9], position well recognized in the aircraft industry.

Time-history response of the structure, exemplified for three freely chosen locations near the explosive charge, was plot in comparison of both materials - piecewise linear static plasticity (mat_24) and Johnson-Cook. The results of the comparison are shown in Figs. 18, 19 and 20.

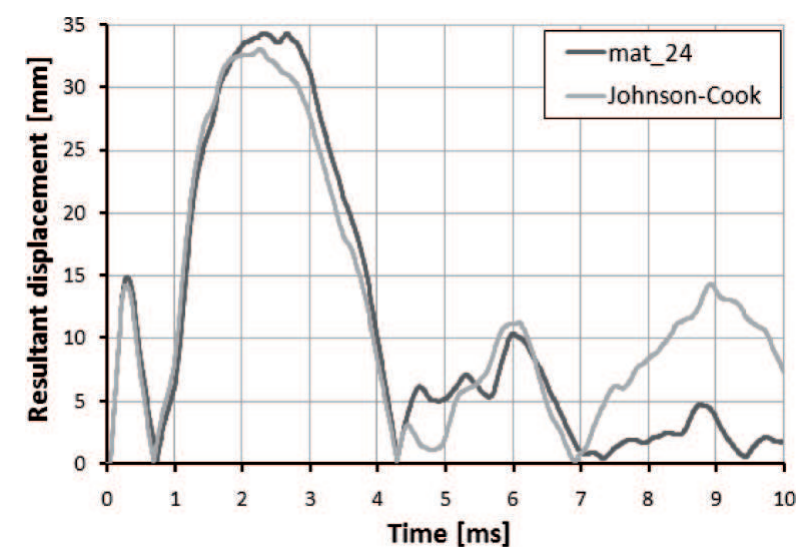

Fig. 18. Resultant displacement of "representative location 1" on the skin

The obtained results clearly show a small/negligible influence of the strain rate on the results. Of course, this statement is valid for the aluminum fuselage, considered here, and for the applied, relatively small explosive charge of mass $m_{0}$. Resulting curves for both material formulations, for previously selected three location are sufficiently close and display the same character. Some - slightly larger - differences in node motion in time can be observed after $7 \mathrm{~ms}$ after explosion for the first and the second node (Figs. 18 and 19), and after $3 \mathrm{~ms}$ for the third node (Fig. 20). 


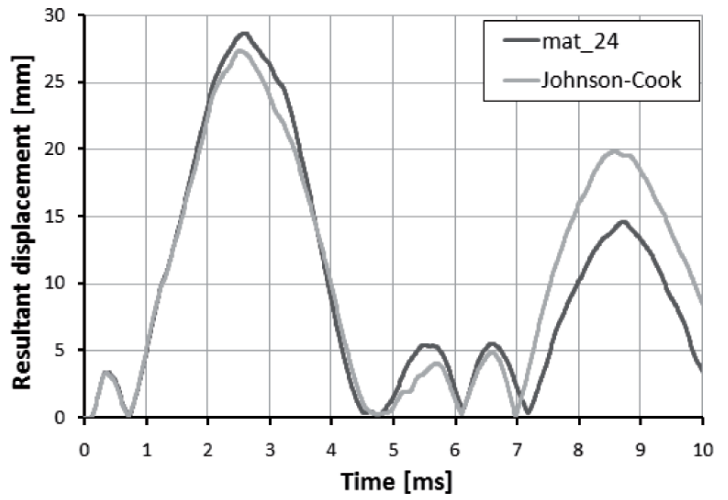

Fig. 19. Resultant displacement of "representative location 2" on the skin

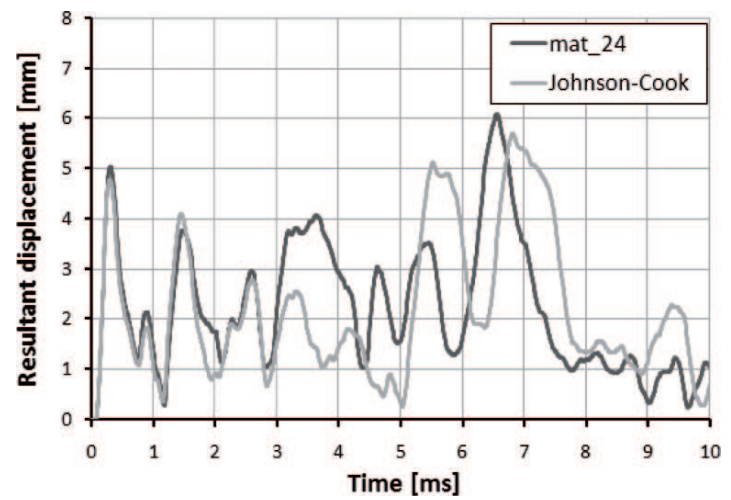

Fig. 20. Resultant displacement of "representative location 3" on the skin

\section{Conclusions}

The studies, not discussed here in detail, have shown very strong sensitivity of the results to the numerical models of materials, formulations of elements etc. The studies confirm also very strong necessity of the correlation of analysis results with experimental data, if available. Without such a correlation, it is difficult to talk about the validation of results obtained from the "explicit" codes.

The effect of reducing the dimensions of the Eulerian mesh (in such a way that the fuselage cross-section is only partially embedded in it) is surprising - the non-physical disturbance in the flow of air (which finally leads to the destruction of the analyzed structure) occurs. This observation, described in the paper, is just one in a row of unexpected parameters sensitivity revealed during the research. The selected effects described in the paper show that the selection of parameters of the Euler domain (including its geometry 
and extent) has a very large influence on quality of results obtained from numerical calculations.

Commercial FE packages offer now broad spectrum of material models. The same concerns very "rich" formulation of element models, which results in number of parameters to set (or to choose from). The variation of these parameters results in wide-spread scatter of obtained results, all of them correct from a formal point of view.

Manuscript received by Editorial Board, July 01, 2011; final version, October 24, 2011.

\section{REFERENCES}

[1] Wentzel C. M., van de Kasteele R. M. and Soetens F.: Investigation of Vulnerability of Aircraft Structure and Materials Towards Cabin Explosions, First International Conference on Damage Tolerance of Aircraft Structures, Delft, 2007.

[2] Ashley S.: Safety in the sky: Designing bomb-resistant baggage containers, Mechanical Engineering, pp. 81-84, June 1992.

[3] Moon Y., Bharatram G., Schimmels S., Venkayya V.: Vulnerability and Survivability Analysis of Aircraft Fuselage Subjected to Internal Detonations, MSC World Users' Conference, Universal City, California, 1995.

[4] Dacko A. and Toczyski J.: Structural Response of a Blast Loaded Fuselage, Journal of KONES, Vol. 17, No. 1, pp. 101-109, 2010.

[5] Habas D. et al.: Selection and Design of Scaled Simplified Sub-Aerostructures, EU Project VULCAN: AST5-CT-2006-031011, VULCAN Deliverable D1.4, Tanagra, 2008.

[6] Hallquist J. O., LS-DYNA V971, LSTC Co., Livermore, California, 2010.

[7] Soutis, C. et al., Computational Simulation of blast effects on flat panels, EU Project VULCAN: AST5-CT-2006-031011, VULCAN 24m Meeting, Barcelona 2008.

[8] Włodarczyk, E., Wstęp do mechaniki wybuchu [Introduction to Physics of Explosion], PWN, Warsaw, 1994.

[9] Lesuer, D., Failure Modeling of Titanium 6Al-4V and Aluminum 2024-T3 With the JohnsonCook Material Model, Report FAA: DOT/FAA/AR-03/57, September 2003.

\section{Analiza wrażliwości kadłuba samolotu na obciążenie wybuchem wewnętrznym}

$$
\text { Streszczenie }
$$

W pracy przedstawiono wybrane aspekty modelowania i symulacji numerycznych odporności struktury cienkościennego kadłuba lotniczego na obciążenia wywołane falą uderzeniową, generowaną przez wewnętrzną detonację ładunku wybuchowego o masie $m_{0}$. Charakterystyki mechaniczne materiałów przyjęto z pomiarów eksperymentalnych. Zastosowano technikę sprzężenia oddziaływań między strukturą a płynem, Arbitrary Lagrangian-Eulerian, z opcją erozji zniszczonych elementów. Przeanalizowano mechanizmy zniszczenia struktury w zależności od lokalizacji ładunku wybuchowego. Rozpatrzono wpływ różnych parametrów modelu obliczeniowego na wyniki analiz. Zbadano również wpływ wymiarów przestrzeni eulerowskiej na wyniki. Wykazano bardzo silną wrażliwość analizy na przyjęte parametry, wybrane sformułowania elementów (opcje), modele materiałów. Wskazuje to na konieczność korelacji symulacji numerycznych z wynikami eksperymentalnymi. Bez możliwości takich porównań trudno mówić o walidacji modelu obliczeniowego. 